\title{
AN LCA MODEL TO ASSESS THE ENVIRONMENTAL IMPROVEMENT OF NEW FARMING SYSTEMS
}

\author{
Paolo Spugnoli, Fabio Baldi, Alessandro Parenti
}

\section{Introduction}

Assessing the environmental impacts of agricultural activities is a fundamental task to be carried out to reach sustainability. In fact, is quite obvious that the achieving of an objective imply the availability of a way of evaluating its attainment and the effectiveness of an improvement action. Among the different approaches, Life Cycle (environmental impact) Assessment (LCA) method is acknowledged to "represent the most rigorous attempt to account for all the environmental impacts" [Hertwich 1996]. LCA methodology has also the advantage of considering the relations between system inputs and environmental impacts [Bailey 1996]. The importance of LCA is confirmed by the fact that ISO (International Society for Standardization) has issued a series of norms (ISO 14000) regarding its use for environmental management [ISO 2000]. It has also been chosen as an evaluation tool in the process of conferring the European Eco-label [Udo de Haes 1997]. Initially applied to industrial production, it has subsequently been extended to the farming sector [Ceuterick 1996]. LCA has been defined as [SETAC 1993] “.... a process to evaluate the environmental impact associated with a product, process or activity by identifying and quantifying energy and material uses and releases into the environment, and to identify and evaluate opportunities to make environmental improvements. The assessment includes the entire life-cycle of product, process or activity, encompassing extracting and processing raw materials, manufacturing, transportation and distribution, use, re-use, maintenance, recycling, and final disposal...".

To carry out a LCA of the environment impacts of a process requires, first: the availability of data expressing the environment effects of every unit of input

Paper received 18.03.2009; accepted 05.10.2009

Prof. Ing. Paolo Spugnoli, Full Professor; Prof. Fabio Baldi Associate Professor; Prof. Alessandro PARENTI, Associate Professor. and output of the process and second: a software helping in the hard computational work. At the moment, there are several software and data-bases for the purpose, the more used of which in Europe are: SimaPro, Umberto, GEMIS, TEAM, Ecoinvent. [Hayashi 2006; SAIC 2006]. In general, they are not free and not specific for agriculture and quite difficult to use without an appropriate learning practice.

With the aim of overcoming these problems, a model and the related implementing software have been developed. This has been done particularly with the intention of providing an instrument that can be used also on the farm in order to assess the environmental impact of agricultural activities and therefore the possible advantages that could be achieved by modifying them. In that perspective the proposed model represents a decision-making tool, which is a central object of LCA applications [Tilman 2000].

The model is based on data and indication that emerge from the final report [Audsley 1997] of the concerted action (AIR3-CT94-2028) promoted by the European Commission with the objective of harmonizing the different approaches used in applying LCA to agriculture. The aim of this paper is to provide a description of the procedure and the results of its application for the environmental evaluation of ecological and integrated production techniques in comparison with conventional technique.

\section{Materials and methods}

\subsection{The model and its implementation}

The defined LCA model is intended primarily for farm management, but since it determines the impact associated with a product and with the agricultural use of land, it can also be used for eco-labeling and for guiding support actions for sustainable agricultural development. The approach is not much different from that of process energy analysis but while in this case to every system input we had to associate the amount of the energy involved, in the case of LCA we had to associate all the different emissions due to its 
production and use which are of different nature and expressed by different unit of measure. A schematic representation of a generic agricultural process and the main interacting system's components, together with the interchange flows, are reported in Fig.1. E.I. represents the Economic Inputs supplied by the Economic System (E. S.), the production of which requires energy subtracted from Primary Sources (P. S.) and involves the emission of impacting substances due to their production (Prod Em). The use of E.I. in the agricultural process - whose primary purpose is the economic output $\mathrm{O}$ - implies the emission due to the use of E.I. (Use Em) as well as some depletion but also restoration - of Environmental Resources (E.R.).

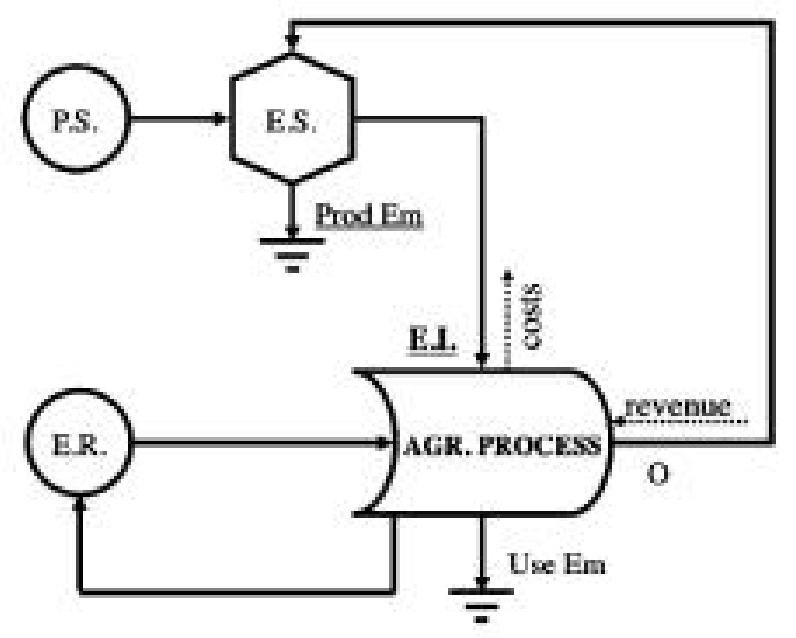

Fig. 1 - System's components and interchanging flows.

The agricultural system's inputs and outputs are subdivided into economic flows and into environmental flows. The economic inputs are organized in classes of principal production factors, namely: energy, machinery, buildings, seeds, fertilizers, pesticides, and complementary materials. The principal factors are then subdivided into sub-groups, according to a tree structure relationship ending with specific commercial goods. This relationship is made up for establishing correspondences with inputs and environmental emissions associated to their production and use. In the reference documentation [Audsley 1997] only 46 types of inputs were considered, insufficient for a general application of the procedure. The major lack regarded pesticides for which only 11 types were mentioned and that we have increased up to 46 . The assignment of the emission values to a specific pesticide not present in the original list has been done by chemical similitude. At the moment a total of 88 input voices are provided. The economic outputs are the marketable farm products and by-products. As to the environmental flows, the outputs are characterized in a series of emissions (in the atmosphere, in the water, in the soil), while for the inputs we considered only the abiotic resource fossil energy associated with the economic inputs (deduced with the energy analysis). The $\mathrm{CO}_{2}$ adsorbed and fixed by the plants is considered apart. Concerning the environmental outputs, the model refers to 71 emissions inferred from the reference documentation [Audsley 1997] for which there are the correspondences both with the system inputs and with the associated environmental impacts. The relations between system inputs and consequent impacts are defined by means of two matrixes, the first one of $88 \times 72$ elements establishing the correspondence between input factors and environmental emissions, the second one of $71 \times 11$ elements establishing the correspondence between emissions and impacts. A fundamental step is the allocation of environmental effects to each production phase referring them to the functional unit. The result is a cause-effect relationship between process-phase and impacts. The model and the related implementing software facilitate this task, requiring the user to provide the necessary information and then automatically making the allocations and processing of the data. The functional unit is a system element quantity respect to which the performances of the productive process is expressed or measured. Generally is a unit of the product itself to be taken as functional unit. In our case, too we took the unit of product, in particular the ton of product harvested, but also the unit of land, a hectare of cultivated field, for its twofold value as a production unit and as a fundamental environmental resource. In fact, it is necessary to refer the data to the unit of land to characterize the different uses of the soil, seen not only as a production factor but also as a product, resulting from different production typologies and techniques. The computational framework and steps of the model are represented in Fig. 2. The central part of calculation being the two matrixes previously described, an electronic sheet support has been used to implement the software.

The procedure makes it possible to assess the impacts referred to the chosen functional unit. These are provided in the form of tables and graphs.

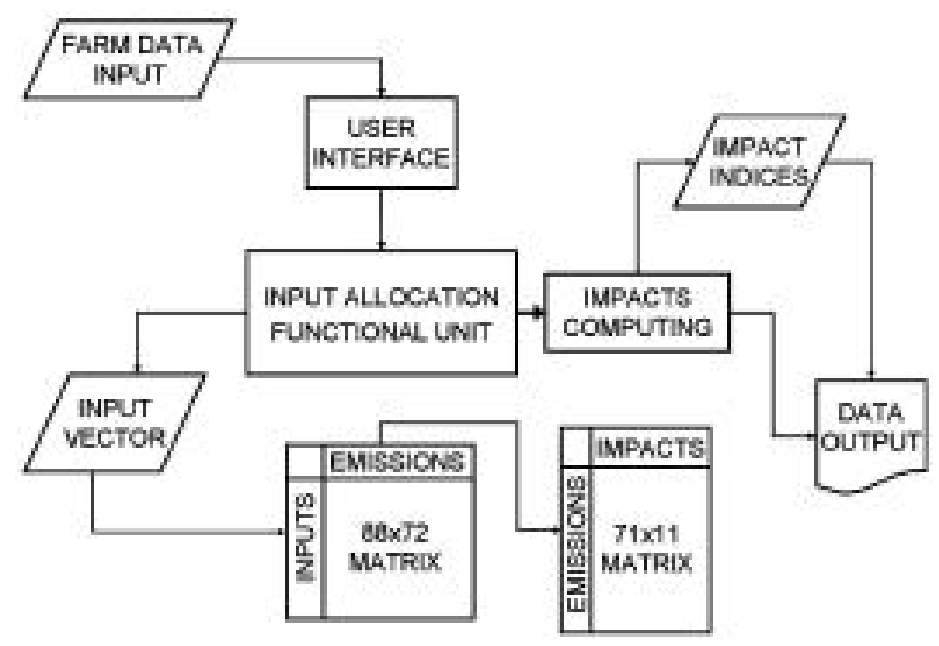

Fig. 2 - Computational framework of the model. 


\subsection{Impact categories and indices}

As indicated in the European harmonization of LCA [Audsley 1997], seven are the impacts categories that have been considered and which we show here for greater clarity, the listed categories are those commonly used in LCA studies [SAIC 2006].

1) Energy Resources Depletion (ERD). Expressed in MJ of total fossil energy required by the production process referred to the unit of cultivated area and to the resulting unit of product.

2) Global Warming Potential (GWP). An increase of certain gases in the atmosphere leads to a global rise in temperature. The gases responsible for this phenomenon are $\mathrm{CO}_{2}, \mathrm{~N}_{2} \mathrm{O}, \mathrm{CH}_{4}$ and aerosols. Their effects are evaluated on a time scale of 20 , 100 and 500 years. In our study, all the emissions relative to the different inputs have been standardized in $\mathrm{kg}$ equivalents of $\mathrm{CO}_{2}$. In our application, only the 500-time scale impact has been considered (indicated as the most representative of the total effect [Audsley 1997]).

3) Acidification Potential (ACID). Acidification is the emission of gases into the air that damage the environment by combining with other chemical molecules and return to the soil in the form of "acid rain". All the emissions of $\mathrm{NOX}, \mathrm{NH}_{3}$ and $\mathrm{SO}_{2}$ relative to the different inputs are expressed in terms of $\mathrm{kg}$ equivalents of $\mathrm{SO}_{2}$.

4) Eutrophication Potential (EUTRO). This is the passage of nutrients, principally through the water cycle but also through the air, to other ecosystems where they alter the development cycle of living beings. This can have undesirable effects from several points of view and in particular that of biodiversity. The main substances responsible for this phenomenon are chemical fertilizers and manure. The inputs relative to these substances have been standardized in $\mathrm{kg}$ equivalents of phosphate.

5) Photochemical Oxidant Formation (OXFOT). Nitrogen oxide reaction with other volatile ecological substances, subjected to the action of UV radiation, leads to the formation of photochemical oxidants, which are the major causes of atmospheric pollution known as smog. Methane and NMVOC (nonmethane volatile ecological compounds), relative to the system under examination have been transformed into $\mathrm{kg}$ equivalents of ethylene.

6) Ecotoxicity Potential (ETP). This is the exposure of ecosystems to toxic substances for the inputs relating to different production systems. The impact considers the effects on the water system and the soil system summed up and expressed in $\mathrm{kg}$ equivalents of zinc. The study examined emissions related to chemical fertilizers and pesticides.

7) Human Toxicity Potential (HTP). This concerns man's exposure to toxic substances. It is subdivided into three effects, air-air, water-water and soilfood and is expression in $\mathrm{kg}$ equivalents of lead. In our evaluation we refer to the total of the three specific impacts. In this case, too the emissions rela- tive to fertilizers manure and pesticides were considered. Particularly important is the incidence of heavy metals contained in chemical fertilizers, which seems to have a considerable effect on the HTP soil-food parameter [Audsley 1997].

Since the aim of the proposed procedure is to provide a tool for the evaluation of the achievable (or achieved) environmental advantages by introducing new production techniques, we thought it appropriate to make a comparison with a reference (conventional) system and to quantify the evaluation in relation to the impacts that it produces. The reference system can be represented by the system actually being used, but also by a production model. For the evaluation of the relative environmental impacts the following equation are used:

$$
S I R l i=1-\frac{2 l i}{(I+\text { linef })}
$$

SIRIi: Single Impact Reduction Index relative to the impact i-th.

$\mathrm{I}_{\mathrm{i}}$ : value of the Impact $\mathrm{i}$-th, with the introduction of the new technique

I. ref: value of the Impact i-th, with the conventional reference technique

SIRI takes on values between -1 and 1 , which will be positive in the case the modified system is better than the conventional one $\left(I_{i}<I_{i} r e f\right)$, negative in the opposite case.

Despite ISO (2000) describes both normalization and weighting of impact indicators as optional elements of LCA, to make easy the interpretation of the results and the comparison between systems, an aggregate index has been defined, the CEI (Comparative Environmental Index), which can be expressed as a weighted average of the SIRI. In symbols:

$$
C E I=\frac{\left.\sum S I R l^{*} C\right)}{\sum G}
$$

where $\mathrm{Ci}$ is a weight coefficient for the impact $\mathrm{i}$. The weight coefficients can be the result of a multicriteria approach that associates a numerical value with the order of importance assigned to the different impact categories. In the present application identical weights of unit value were used.

In this case the CEI began:

$$
C E I=\frac{\sum S I R / S}{7}
$$

being seven the impact categories considered.

The $\mathrm{CO}_{2}$ balance has also been considered and an index similar to that of "energy efficiency", expressed by the ratio between $\mathrm{CO}_{2}$ subtracted from the atmosphere (immobilized in biomass) and $\mathrm{CO}_{2}$ emitted, was evaluated. To this purpose the following coefficient have been taken for the computation of the atmospheric $\mathrm{CO}_{2}$ immobilized in biomass: $1 \mathrm{~g}$ dry substance $=0.5 \mathrm{~g}$ of $\mathrm{C}=1.83 \mathrm{~g}$ of $\mathrm{CO}_{2}$ (atmospheric) [Schlesinger 1991]. 


\begin{tabular}{cccccccc}
\hline Factors & $\begin{array}{c}\text { GWP } \\
\mathrm{kg} \mathrm{CO} \text { eq }\end{array}$ & $\begin{array}{c}\text { ACID } \\
\mathrm{kg} \mathrm{SO}\end{array}$ & $\begin{array}{c}\text { EUTROF } \\
\mathrm{kg} \text { phos. eq }\end{array}$ & $\begin{array}{c}\text { OXFOT } \\
\mathrm{kg} \text { ethyl. eq }\end{array}$ & $\begin{array}{c}\text { HTPtot } \\
\mathrm{kg} \mathrm{eq} \mathrm{Pb}\end{array}$ & $\begin{array}{c}\text { ETPtot } \\
\mathrm{kg} \mathrm{eq} \mathrm{Zn}\end{array}$ & $\begin{array}{c}\text { E.R.D. } \\
\text { MJ }\end{array}$ \\
\hline Energy & 286.79 & 4.01 & 0.64 & 0.61 & 0.22 & 0.01 & 3819.91 \\
Machincry & 98.26 & 0.92 & 0.03 & 0.06 & 0.53 & 0.00 & 1519.78 \\
Building & 49.64 & 0.59 & 0.02 & 0.04 & 0.17 & 0.00 & 630.93 \\
Seeds & 3.04 & 0.03 & 0.00 & 0.00 & 0.00 & 0.00 & 48.51 \\
Fertilizers & 660.15 & 20.50 & 7.33 & 0.34 & 6798.87 & 10.31 & 9348.47 \\
Pesticides & 15.12 & 0.18 & 0.01 & 0.02 & 0.06 & 2.15 & 301.72 \\
Total & 1113.00 & 26.23 & 8.02 & 1.06 & 6799.85 & 12.48 & 15669.32 \\
\hline
\end{tabular}

TABLE 1 - Sunflower, conventional technique (reference), crop impact per hectar.

\subsection{Tests data}

The model has been applied to compare integrate and ecological agricultural practices with conventional one. Data refer to the experimental fields of the Montepaldi farm belonging to Florence University where a research is underway on integrated and ecological cultivation prototypes along with a conventional system as a reference [Vazzana 1997]. Wheat and sunflower are the main crops. The main characteristics of the three growing systems, which cover an area of approximately 15 ha, are described in the following.

- Conventional or intensive farming system. The two-yearly rotation adopted in the conventional farming system is done with sunflower as the renewal crop followed by wheat.

- Integrated farming system. It is based on four-year rotation of sunflower, wheat, broad beans, and wheat. The quantity of chemical fertilizers used decreases considerably. The use of plant protection products is also reduced.

- Ecological or organic farming system. This is based on four yearly rotation of sunflower, wheat, broad beans, broad beans. No chemicals are used.

\section{Results}

For the sake of simplicity, but without any loss in generality, only data regarding sunflower are reported in the following.

As an example, tab. 1 contains the values of the impacts per hectare encountered for sunflower grown according to the conventional technique. The evaluations are made for production factor typologies. This in particular helps to highlight the relative importance of the factors in producing impacts. In this specific case, the preponderance of the chemical inputs and in particular fertilizers in creating impacts is immediately evident. The high value associated with fertilizers is particularly that of HTP due to the effect of heavy metals. Fig. 3 shows graphs comparing the impacts produced by the ecological and the integrated systems compared with the conventional system for sunflower. The values are those of the SIRI index and express the degree of improvement achieved (reduced impact). We point out that, while in the case of values referred to the unit of area cultivated the two systems bring an improvement for the various categories of input, greater for the ecological technique, in the case of the values referred to the unit of product some impacts
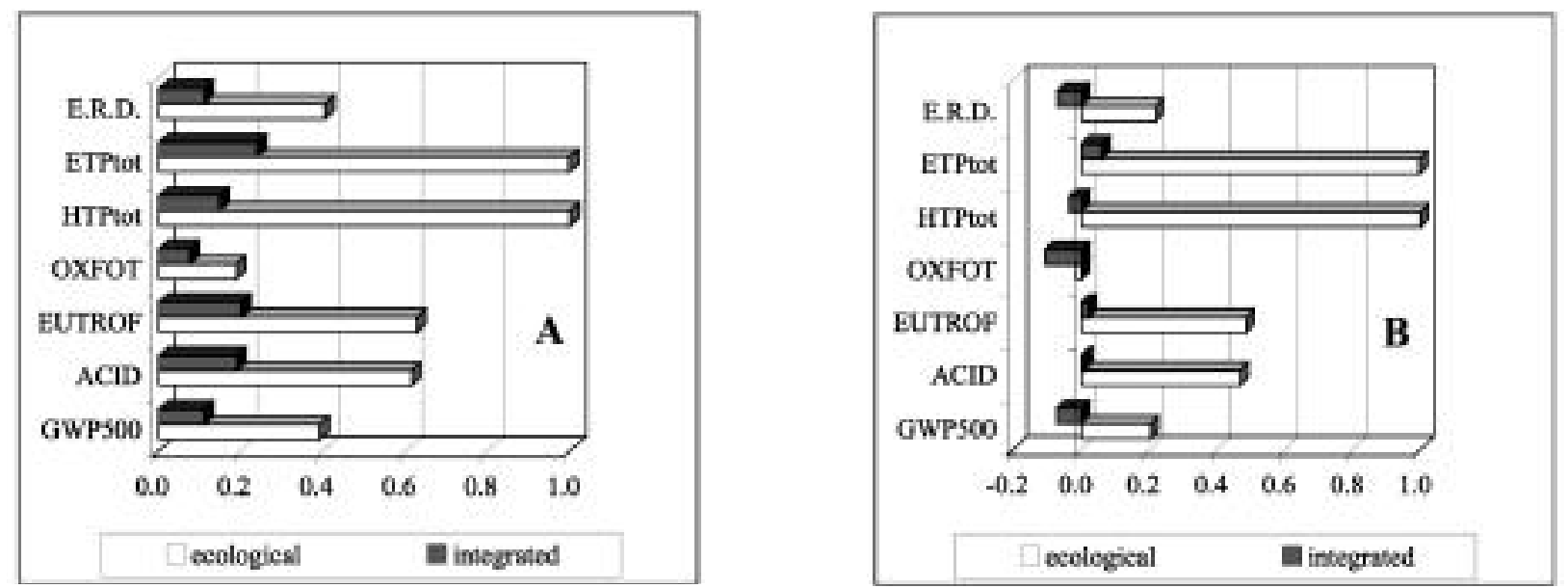

Fig. 3 - Sunflower, SIRI index of impact reduction: A, per unit of area (ha); B per unit of product (Mg). 


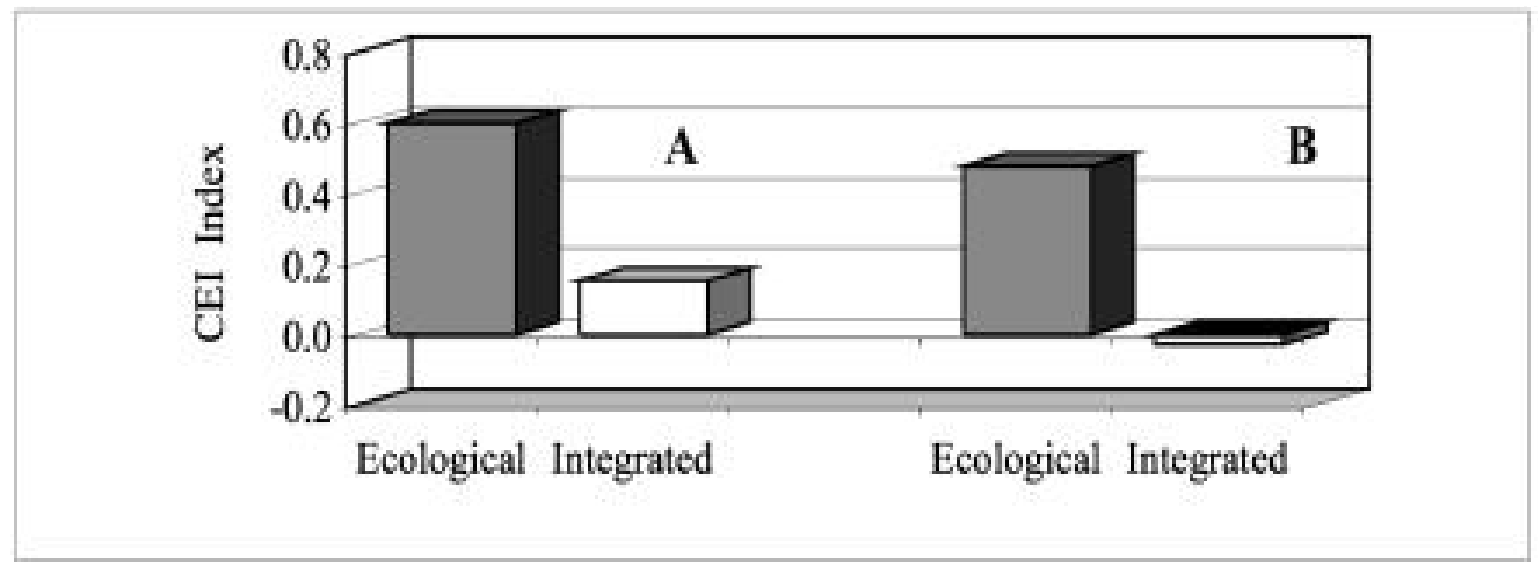

Fig. 4 - Values of CEI environmental index for sunflower: A, per unit of area (ha) B, per unit of product (Mg).

are higher (negative SIRI values); i.e. a situation arises in which it is difficult to express an opinion.

This is the main reason for introducing the CEI index previously defined, the use of which enables the results of the analysis to be represented as shown in Fig. 4.

The graphs clearly show that for sunflower the overall impact per unit of product with the integrated technique exceeds that obtained with the conventional technique. The worst performance when the index is

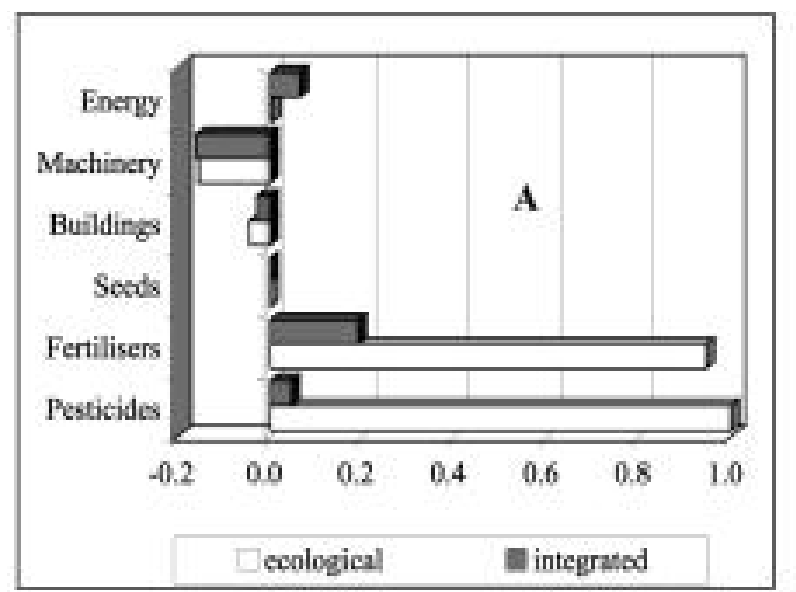

referred to the unit of product is due to the reduction of yield resulted with new techniques. The relative importance of the different production factors in forming the overall CEI index value is highlighted in Fig. 5: while for ecological technique the higher use of machinery is compensated by the reduction of fertilizers and pesticides, on the contrary in the case of integrated technique this does not happen.

The CEI index has also been disaggregated with respect to the main field operations (Fig. 6): it may be

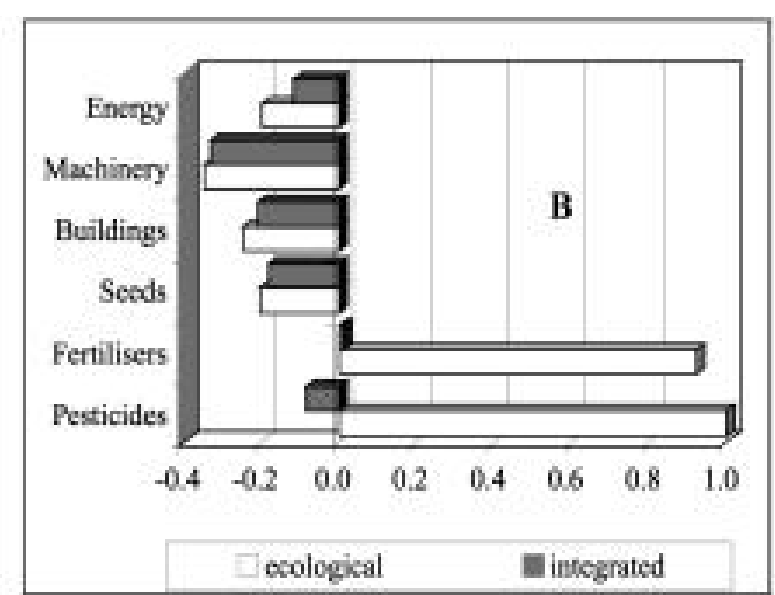

Fig. 5 - CEI index of the production factors in sunflower: A, per unit of area (ha); B, per unit of product $(\mathrm{Mg})$.
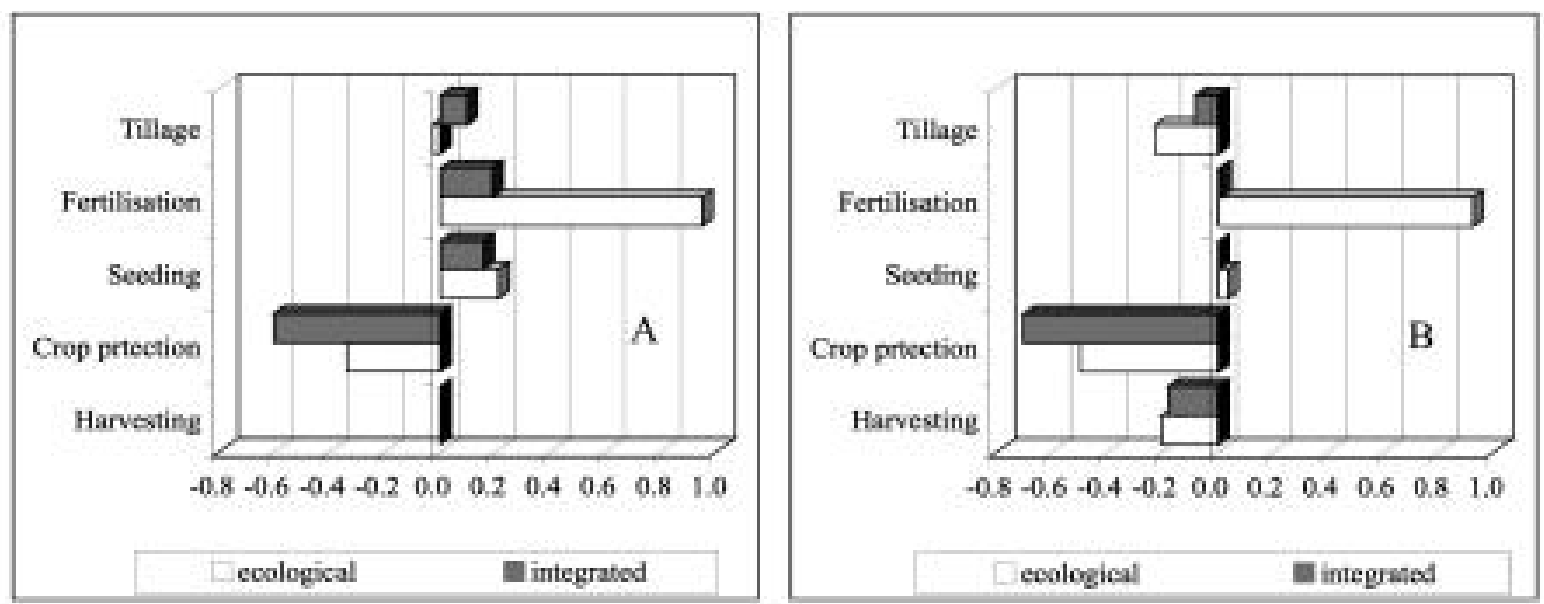

Fig. 6 - CEI index of the main field operation in sunflower: A, per unit of area (ha); B, per unit of product (Mg). 


\begin{tabular}{|c|c|c|c|c|c|c|}
\hline \multirow{2}{*}{$\begin{array}{l}\text { Farming } \\
\text { system }\end{array}$} & \multicolumn{3}{|c|}{ per unit of area } & \multicolumn{2}{|c|}{ per unit of product } & \multirow{2}{*}{$\begin{array}{l}\text { Energy } \\
\text { efficiency }\end{array}$} \\
\hline & $\begin{array}{l}\text { Input } \\
\mathrm{MJ} / \mathrm{ha}\end{array}$ & $\begin{array}{l}\text { Output } \\
\mathrm{MJ} / \mathrm{ha}\end{array}$ & $\begin{array}{c}\text { Yicld } \\
\mathrm{kg}\end{array}$ & $\begin{array}{l}\text { Input } \\
\mathrm{MJ} / \mathrm{kg}\end{array}$ & $\begin{array}{l}\text { Output } \\
\mathrm{MJ} / \mathrm{kg}\end{array}$ & \\
\hline Conventional & 15669 & 54064 & 2480 & 6.32 & 21.80 & 3.45 \\
\hline Ecological & 6650 & 35752 & 1640 & 4.06 & 21.80 & 5.38 \\
\hline Integrated & 12574 & 37496 & 1720 & 7,31 & 21.80 & 2.98 \\
\hline
\end{tabular}

TABLE 2 - Sunflower energy balance and efficiency.

\begin{tabular}{ccccccc}
\hline \multirow{2}{*}{$\begin{array}{c}\text { Farming } \\
\text { system }\end{array}$} & \multicolumn{3}{c}{ per unit of area } & \multicolumn{4}{c}{ per unit of product } & \multirow{2}{\mathrm{GWP}_{2}}{} \\
\cline { 2 - 5 } & $\begin{array}{c}\text { Absorption } \\
\mathrm{kg} \mathrm{CO} \mathrm{CO}_{2} \text { eq }\end{array}$ & $\begin{array}{c}\text { Yield } \\
\mathrm{kg}\end{array}$ & $\begin{array}{c}\mathrm{GWP} \\
\mathrm{kg} \mathrm{CO} \text { eq }\end{array}$ & $\begin{array}{c}\mathrm{Absorption} \\
\mathrm{kg} \mathrm{CO} \text { eq }\end{array}$ & $\begin{array}{c}\mathrm{CO}_{2} \\
\text { efficiency }\end{array}$ \\
\hline Conventional & 1113.00 & 3948.41 & 2480.00 & 448.79 & 1592.10 & 3.55 \\
Ecological & 487.35 & 2611.04 & 1640.00 & 297.16 & 1592.10 & 5.36 \\
Integrated & 893.75 & 2738.41 & 1720.00 & 519.62 & 1592.10 & 3.06 \\
\hline
\end{tabular}

TABLE 3 - Sunflower $\mathrm{CO}_{2}$ balance and efficiency.

seen that the operations that mainly increase the impact of the new techniques are those for crop protection due to the higher use of mechanical work in substitution of pesticides. Of course, this result is strongly affected by the methodology used to compute the quantity of emissions and the associated impacts of the different factors as well as the weight coefficient used to compute CEI index (assumed equal to the unity in the present application), which may express the different importance, or gravity, given to the different impacts. Eventually, energy and $\mathrm{CO}_{2}$ evaluation for sunflower are reported in Tab. 2 and Tab. 3, respectively. It's worth to point out that both energy and $\mathrm{CO}_{2}$ efficiency reflect the overall impact evaluation made by the CEI index, which is substantially a measure of the environmental improvement achieved.

\section{Conclusion}

The proposed model, together with the implementing software, makes the application of the LCA methodology sufficiently simple to use as an instrument to monitor the environmental impacts deriving from agricultural activities. It has the advantage to put in relation production factors, as well as farm operations, with the environmental effects, and thus to be used also to simulate or foreseen the effects of process modification (inputs, technique). The present application of LCA to agriculture does not solve the problem of environmental inputs made up of the system's intrinsic resources, like soil fertility or biodiversity. This is certainly a shortcoming, though the effects are lessened if one considers the fact that an indirect assessment of the use of the system's internal resources is given by the variation in the external re- sources (economic inputs) necessary to maintain production. Energy analysis parameters like efficiency, confirm to be good indicators of the overall environmental impact of an agricultural system. The same seems to stand also for $\mathrm{CO}_{2}$ efficiency.

\section{References}

Audsley, E. (Coordinator) 1997. Harmonization of Environmental Life Cycle Assessment for Agriculture. Final Report Concerted Action AIR3-CT94-2028, European Commission DG VI Agriculture, Pp 103.

Bailey, P., Gough, C., Chadwick, M. And Mcgranahan, G. 1996. Methods for Integrated Environmental Assessment: Research Directions for the European Union. Stockholm Environment Institute, Stockholm, Pp 33.

Ceuterick, D. (Editor), Conference on Application of Life Cycle Assessment in Agriculture, Food and Non-Food Agroindustry and Forestry: Achievements and Prospects; Draft, 4-5 April 1996, Brussels.

Hayashi K., Gaillard G. \& Nemecek T., 2006. Life Cycle Assessment of Agricultural Production Systems: Current Issues and Future Perspectives. In: Hu SH \& BejosanoGloria C. (Eds.), Good Agricultural Practice (GAP) In Asia and Oceania. Food and Fertilizer Technology Center, Taipei, Taiwan, ROC, Pp. 98-110.

Hertwich, E.G., Pease, W.S.Y., Koshland, C.P., 1996. Evaluating The Environmental Impact Of Products And Production Processes: A Comparison Of Six Methods, The Science Of The Total Environment, 196: 13-29.

ISO (International Organization For Standardization), 2000.Environmental Management - Life Cycle Assessment - Life Cycle Impact Assessment. International Standard ISO 14042:2000.ISO, Geneva.

SAIC, 2006. Life Cycle Assessment: Principles and Practice. Http://Www.Epa.Gov/ORD/NRMRL/Lcaccess. 
Schlesinger, W.H. 1991. Biogeochemistry, an Analysis of Global Change. New York, USA, Academic Press.

SETAC (1993), Guidelines for Life-Cycle Assessment: A "Code of Practice", Society for Environmental Toxicology and Chemistry, Brussels and Pensacola.

Tillman A.M., Significance Of Decision-Making For LCA Methodology, Environ. Impact Assessment Rev. 20 (2000) 113-123.

Udo De Haes, H.A. (Chairman), 1997. Guidelines for the Application of Life-Cycle Assessment in the EU EcoLabel Award Scheme. A Report Prepared for the European Commission by the "Groupe Des Sages".

Vazzana C., Raso E., Pieri S., 1997. Una nuova metodologia europea per la progettazione e gestione di agrosistemi integrati ed ecologici: applicazione in un area agricola Toscana. Riv. di Agron., 31, 2.

\section{SUMMARY}

The environmental impact of new farming practices is compared with that of conventional one. The approach is that of LCA and the assessing procedure is based on two cross-interaction matrices relating sys- tem inputs with emissions and impacts. With the aim to allow its application also at farm level by non-expert users, the procedure has been implemented in software that facilitate it use. Furthermore, the definition of standard impact values and a total environmental effects index make it easier to compare different systems and to evaluate the improvement achieved with a new agricultural practice. As an example, the model has been applied to compare the environmental effects generated in the production of sunflower using ecological, integrated and conventional farming techniques. Both Ecological and Integrated technique present lower impact than conventional even if for some specific impact the results are inverted. The application highlights the importance of the functional unit: when environmental effects are referred to the unit of production (ton), the total impact of the integrated technique is higher than the conventional one. Energy and $\mathrm{CO}_{2}$ efficiency are also computed, which are resulted to be good indicators of the overall environmental impact of a cultivation system.

Keywords: Environmental impact, LCA, Modeling. 
